\title{
CONSIDERAÇÕES SOBRE A RESPONSABILIDADE CIVIL DO ESTADO POR FATOS DOS SEUS AGENTES *
}

\author{
ALCIDES ALBERTO MUNHOZ DA CUNHA
}

\section{SUMÃRIO}

1 - INTRODUÇÃO

II - IMPUTAÇÃO E RESPONSABILIDADE

III - FUNDAMENTO DE FATO DA IMPUTAÇĀO

IV - FUNDAMENTO JURÍDICO DA IMPUTAÇĀO - TEORIAS

V - QUALIDADE DE ORGĀO

VI - FUNDAMENTO DA RESPONSABILIDADE TEORIAS

VII - CUlPA DO AGENTE E CULPA DO SERVIÇO

VIII - RESPONSABILIDADE E CAUSALIDADE

*Trabalho apresentado à Disciplina de Direito Administrativo do Curso de Pós-graduação em Direito do Setor de Ciências Jurídicas da UFPR. 


\section{I - INTRODUÇĀO}

O tema da responsabilidade civil do Estado é dos mais conhecidos e debatidos no âmbito do direito público, porque traz consigo o caráter de constante atualidade.

Esta atualidade decorre sabidamente da singularidade da posição que o Estado ocupa em face dos ordenamentos jurídicos contemporâneos.

No Estado de Direito, constitucional, primeiramente segundo o modelo do Estado Liberal, prevalecia ainda a tese da irresponsabilidade do Estado, ou porque se entendia que o Estado, sendo um ente moral não podia ter vontade para praticar atos ilícitos danosos a terceiros, ou porque se sustentava que tal responsabilidade era incompatível com a sua soberania.

Esta solução, segundo RIVERO (1), perdurou até a metade do século XIX e embora fosse rigorosa para os particulares, era aceitável na prática, na medida em que o Estado Liberal, limitando'estreitamente as suas atividades, tinha relativamente poucas ocasiões de causar danos.

Todavia, as mutações socio-econômicas que se sucederam em decorrência da revolução industrial e do aumento acelerado das populações, deram ensejo ao surgimento do Estado Providência, de caráter nitidamente intervencionsita, dando origem a relações jurídicas inusitadas.

Com isso, aumentaram-se as hipóteses de lesões, por parte do Estado, a interesses juridicamente protegidos dos particulares, seus administrados. Admitiu-se, então, a sua responsabilidade civil, cujo campo de incidência foi crescendo progressivamente, notadamente no campo das suas relações extra-contratuais.

Com efeito, ressalta CELSO ANTONIO BANDEIRA DE MELLO (2), "seja porque os deveres públicos do Estado o colocam permanentemente na posição de obrigado a prestações multifárias das quais não se pode furtar, pena de ofender o direito ou omitir-se em sua missão própria, seja porque o seu contato omnímodo e constante com os administrados Ihe propicia acarretar prejuízos em escala macroscópica, o certo é que a responsabilidade estatal por danos há de possuir fisionomia própria, que reflita a singularidade de sua posição jurídica".

A despeito da evolução processada neste campo, admitindose a responsabilidade do Estado, primeiramente fundada na culpa pessoal dos seus agentes, depois na culpa impessoal ou administrativa ("faute du service") e, finalmente fundada no risco, cuja 
noção prescinde da culpa, subsistem ainda controvérsias ponderáveis, na doutrina e notadamente na jurisprudência, sobre a necessidade ou não de se fundar a responsabilidade estatal na culpa, depois de admitida a responsabilidade fundada no risco.

Os fundamentos da responsabilidade objetiva e subjetiva não se excluem, todavia, antes se combinam juridicamente, para ampliar as hipóteses de incidência da responsabilidade civil estatal.

A pacificação da controvérsia, porém, segundo se acredita, depende da distinção que deve ser necessariamente feita entre imputação e responsabilidade do Estado.

Pretende-se, então, neste breve ensaio, demonstrar a relevância desta distinção, para a exata compreensão do regime da responsabilidade civil extracontratual do Estado, por fatos dos seus agentes.

\section{II - IMPUTAÇĀO E RESPONSABILIDADE}

Existe realmente alguma confusão entre os fundamentos pelos quais se opera a imputação de um fato ao Estado e os fundamentos pelos quais se positiva a sua responsabilidade perante o terceiro lesado.

Uma coisa será determinar se o fato danoso é atribuível ao Estado ou a outrem, a esta ou aquela pessoa jurídica de direito público ou privado, ou mesmo a uma pessoa natural. Coisa bem diversa será estabelecer o fundamento da responsabilidade, ou seja, o motivo que justificará a imposição de reparação do dano em confronto da pessoa imputada.

Entre as noções de imputação e responsabilidade existe pois uma relação lógica de antecedente e consequente.

Imputação, palavra derivada do latim, imputatio ou imputare, tem o significado de levar em conta, atribuir e, segundo DE PLÁCIDO E SILVA (3), implica na declaração ou atribuição de que uma determinada ação pertence a uma determinada pessoa. Implica, ainda, segundo o mesmo autor, na indicação, teoricamente, de quem deva ser chamado à responsabilidade, por the ser atribuída a qualidade de autor ou causador do ato ou do fato imputável.

Responsabilidade, por sua vez, na linguagem do direito, designa sempre um dever jurídico de suportar as sanções legais que Ihe são impostas (4), sendo que a expressão responsabilidade civil, de que aqui se ocupa, designa, mais especificamente, a obri- 
gação de reparar o dano ou ressarcir o dano injustamente causado a outrem (5).

Como se vê, a imputação é um pressuposto da responsabilidade. Por ela se procura identificar o sujeito que, à luz do ordenamento jurídico, deverá se submeter à investigação da responsabilidade, por fato que lhe é atribuído.

Diz-se então que a imputação é direta, quando se atribui à pessoa um fato próprio e indireta, quando se Ihe atribui um fato de outrem.

De outro lado, diz-se que a responsabilidade é subjetiva ou objetiva, conforme o dever de reparação tenha ou não por fundamento a culpa.

O fato que se pretende enfatizar aqui, por ora, é simplesmente que os qualificativos direta e indireta referem-se aos fundamentos da imputação, enquanto os qualificativos subjetiva e objetiva dizem respeito aos fundamentos da própria responsabilidade.

Em suma, não se deve confundir um pressuposto da responsabilidade com os fundamentos da sua própria liquidação. Neste equívoco, porém, incorreram muitos autores.

PIERRE WIGNY (6), por exemplo, incidiu na confusão, afirmando que os pressupostos da responsabilidade civil são o prejuízo (existência de um dano), a lesão de um direito (comprometimento de uma situação juridicamente protegida em relação à vítima, a culpa (porque pode ocorrer lesão ao direito sem culpa) e, por fim, a causalidade.

MARIA HELENA DINIZ (7), denota que em semelhante confusão incorreu SAVATIER, apresentando a culpa e a imputabilidade como pressupostos da responsabilidade civil e também TRABUCHI, que incluiu como pressupostos o fato danoso, o dano, a antijuridicidade ou a culpabilidade.

Parodiando CELSO ANTONIO BANDEIRA DE MELLO (8), a propósito do seu discurso sobre a divergência doutrinária dos elementos que compõe o ato administrativo, pode-se dizer que muitas vezes as divergências não são assim substanciais, mas apenas de natureza terminológica, visto que muitos autores passam a englobar em um único pressuposto certos aspéctos que por outros são desdobrados.

Basicamente é de se concordar com RIVERO (9), PAUL DUEZ e GUY DEBEYRE (10) MARTHY e RAUNAUD (11), os quais arrolam como pressupostos a existência de um dano para o terceiro, a existência de um fato danoso imputado a uma pessoa, 
como ao Estado e, por fim, um nexo causal entre os dois primeiros pressupostos.

É de se entender, porém, que os pressupostos da responsabilidade civil haverão de ser necessariamente aqueles que façam supor a existência de uma relação jurídica ressarcitória. Sob esta inspiração, acredita-se que tais pressopostos poderão ser enunciados e explicados de uma maneira mais precisa, como se verá a seguir:

10.) existência de um dano ilegítimo para o terceiro (administrado). Este é o pressuposto que corresponde a um dos sujeitos indispensáveis da suposta relação jurídica. Por dano ilegítimo há de se compreender aquele que, além de certo (não eventual) e especial (superação dos incovenientes comuns a que todos estão sujeitos pela vida em sociedade), apresentese como violador de uma situação juridicamente protegida;

20.) existência de um fato danoso imputado a uma pessoa (Estado). Este é pressuposto da imputação a que se aludiu e que pertine ao outro sujeito indispensável da mesma relação jurídica ressarcitória de que se cogita;

30.) afirmação de uma relação jurídica, envolvendo os dois primeiros pressupostos. Não se trata, frise-se, da causalidade propriamente, dita, pois esta implicará, conforme se procurará demonstrar mais adiante, na liquidação da própria responsabilidade. E nesse sentido, causalidade não poderá ser considerada mero pressuposto. Pressuposto será então a mera afirmação de uma relação jurídica, compreendendo a alegada situação da vítima do dano ilegítimo e a situação do autor do fato danoso.

\section{III - FUNDAMENTO DE FATO DA IMPUTAÇĀO}

O Estado é uma realidade. Todavia, como qualquer entidade moral ou coletiva é, quanto à essência, uma realidade abstrata ou, como diria CELSO ANTONIO BANDEIRA DE MELLO (12), um ser de razão.

O Estado moderno, porém, transparece submetido a uma ordem jurídica constitucional, que the confere o poder-dever de integrar relações jurídicas, como sujjeito de direitos e de obrigações. E surge então o Estado como pessoa jurídica. Mas nem por isso ele passa a ter vontade ou ação "no sentido de 
manifestação psicológica ou vida animítica próprias. Estas, só os seres biológicos as possuem".(13)

Decorre daí que no plano da realidade, puramente física ou fisiopsíquica, ao Estado, bem como a qualquer pessoa jurídica, não se pode imputar qualquer fato.

"Une persone civile ne peut avoir par ellemême des volitions ni exercer une activité. Des êtres humains doivent agir pour son compte". Com estas poucas palavras PIERRE WIGNY (14) posiciona toda a problemática da imputação de um fato ao Estado, como pessoa jurídica que é. A imputação terá então sempre e necessariamente como fundamento de fato um fato do homem, vale dizer, um ato ou uma omissão da pessoa humana.

Mesmo quando se cogita do chamado fato das coisas, animadas ou inanimadas, não é possível pensar que possa haver responsabilidade civil sem que haja o fundamento fático e indispensável de um fato do homem, como bem adverte MARIO MOACIR PORTO (15).

Quanto às coisas inanimadas torna-se óbvio que não podem causar danos por si mesmas. A propósito, AGUIAR DIAS (16) já afirmava que "não há nada tão incongruente como expressar em responsabilidade por fato da coisa a que deriva de acidentes ocorridos com veículos ou objetos de nossa propriedade ou sob nossa guarda. Porque a coisa não é capaz de fatos; e todos os que ocorrem causando danos a terceiro, por intermédio de coisa, são, realmente, consequência ou de falta de vigilância ou de prudência".

O mesmo raciocínio há que ser aplicado em relação às coisas animadas, ao chamado fato do animal, sempre que o mesmo devesse estar sob a guarda ou vigilância de alguém.

Oportuna também se faz aqui uma breve alusão ao chamado fato da natureza. Um fato tal, considerado isoladamente, não dará ensejo à imputação de quem quer que seja e, consequentemente, não haverá que se falar em responsabilização. A imputação e, eventualmente, a responsabilidade, dependerá sempre da associação deste fato da natureza a um fato do homem, tal como o de haver este criado uma condição propiciatória de dano.

É o que se depreende da lição de CELSO ANTONIO BANDEIRA DE MELLO (17), quando cita os exemplos seguintes: os danos, nas vizinhanças, oriundos da explosão em depósito militar em decorrência de raio; lesões radioativas oriundas de vazamento em central nuclear, cujo equipamento protetor derrocou por avalancha ou qualquer outro fenômeno da natureza. "Com efeito, em todos estes casos o dano liga-se, embora 
mediatamente, a um comportamento positivo do Estado. Sua atuação é o termo inicial de um desdobramento que desemboca no evento lesivo, incidivelmente ligado aos antecedentes criados pelo Estado".

Uma vez demonstrado o fundamento de fato da imputação, que é sempre um fato do homem, cumpre examinar outro aspecto da questão, que diz respeito ao fundamento jurídico da imputação, a propósito do que surgiram diferentes teorias.

\section{IV - FUNDAMENTO JURIDDICO DA IMPUTAÇÃO - TEORIAS}

Como disse SERPA LOPES (18) "a pessoa jurídica, sendo capaz de direitos e obrigações, necessita de manifestar a sua vontade no sentido de poder exercitar os direitos que the assistem ou cumprir as obrigações assumidas. Desaparelhada, como está, de um elemento animítico, tem necessidade de se prevalecer de um meio que realize aquela exteriorização tão necessária à realização dos atributos de sua personalidade. Outro recurso não tem, senão o de valer-se de uma entidade física, natural, para que essa vontade se manifeste na direção dos seus interesses. Sobre qual o papel e qualidade do que age com tal função, é que a doutrina diverge profundamente, dividindo-se em dois campos opostos: os que concebem a pessoa jurídica como ficção, para os quais o problema carece de importância, porque entendem que a idéia de representação tudo resolve; os organicistas, que repelem, por inajustável, a representação para buscarem a solução do problema na idéia de órgão".

As teorias a que alude o autor sintetizam o pensamento de duas grandes correntes, a dos idealistas e dos realistas, que procurando explicar o fenômeno da imputação de vontade às pessoas jurídicas e, portanto de sua capacidade, explicam também, em conseqüência, como se opera em confronto destas mesmas pessoas a imputação de um fato, posto que este, em última análise, é um fato de vontade.

A teoria da ficção legal, defendida por SAVIGNY e que desfrutou de largo prestígio no século passado, considerava a pessoa jurídica como uma entidade artificial, uma invenção da lei ou da doutrina. Daí que o legislador, embora lhe conferisse personalidade jurídica para a consecução de fins úteis ao homem, não podia, porém, conferir-Ihe capacidade, eis que esta seria um atributo próprio das pessoas físicas. Concluia-se, então, que a 
pessoa jurídica somente poderia atuar mediante representantes legais, à semelhança do que ocorria com a representação de incapazes.

Esta teoria fundamentou, num primeiro passo, a tese da impossibilidade de imputação de um fato danoso ao Estado e, paralelamente, a tese da imputação do fato exclusivamente aos seus representantes (agentes ou funcionários). Argumentava-se, então, que o Estado, sendo pessoa moral, não tinha vontade efetiva e que, agindo através de representantes, não se poderia supor que estes estivessem autorizados pela lei a praticar fatos danosos, mas somente fatos úteis. Os fatos danosos seriam pois direta e exclusivamente imputados aos representantes.

A teoria da ficção, porém, já foi definitivamente superada. De um lado porque, como disse CAIO MARIO (19), considerando a personalidade do Estado como uma ficção da lei, ter-se-ia que admitir, incoerentemente, que a própria lei seria fictícia, porquanto ato do Estado. De outro lado, a incapacidade jurídica não implica necessariamente na ficção da personalidade, como supunha a teoria, tanto que os incapazes, os interditos, são sujeitos de direito.

Mas surgiram as teorias realistas ou organicistas, em contraposição àquela da ficção. Tais teorias partiram da proposição de que as pessoas jurídicas são organismos morais que, pela ação do direito, institucionalizam-se. Como salientouPIERRE WIGNY(20), fundam-se elas num antropoformismo audacioso. A existência das pessoas jurídicas não decorre de uma ficção, pois elas se apresentam como uma realidade, formada por relações de seres substanciais, ou seja, pessoas físicas, que transparecem, segundo aludiu OSWALDO ARANHA BANDEIRA DE MELLO (21), como centro de atribuições ou operações que atuam funcionalmente em nome das pessoas jurídicas.

Mais uma vez é de se consultar os ensinamentos de SERPA LOPES (22), quando distingue com nitidez o modo como se opera nas diferentes teorias, a imputação de vontade, e consequentemente a imputação de um fato, às pessoas jurídicas.

Diz ele que o representante se vincula ao representado por uma relação externa, ao passo que o órgão é imanente à constituição interna da pessoa jurídica; representante e representado são dois sujeitos, ao passo que ente e órgão (ou funcionário) formam uma só pessoa; a qualidade de representante pode se originar de um ato jurídico ou da lei, ao passo que a de órgão dimana da própria constituição da pessoa moral. 
As teorias organicistas procuraram explicar essencialmente 0 fenômeno da imputação de vontade às pessoas jurídicas. Mas, num primeiro momento, a aplicação ou aceitação destas teorias não acarretou nenhuma novidade na questão da imputação de um fato a estas mesmas pessoas.

Embora admitindo que as pessoas jurídicas tinham vontade própria, considerava-se que os fatos praticados por seus agentes eram ainda fatos dos representantes ou prepostos por ela escolhidos.

No campo da responsabilidade civil admitia-se, então, que uma pessoa jurídica poderia ser chamada à responsabilidade apenas por fato de outrem, seus representantes ou prepostos. Firmava-se então a posição da imputação indireta.

Quanto à responsabilidade civil estatal não se adotou de imediato a mesma solução. Continuava-se a sustentar a tese da impossibilidade de imputação a ele de um fato danoso praticado por seus agentes. $O$ fundamento, porém, não seria mais a falta de vontade das pessoas jurídicas em agir contrariamente ao direito. Houve então o recurso à noção de soberania. $O$ Estado, como ente soberano, não poderia ser chamado à responsabilidade pelo fato dos seus agentes.

Posteriormente, a responsabilidade civil do Estado passou a acompanhar, qunto ao seu fundamento, o modelo civilista, admitindo a imputação indireta.

Todavia, aquela singularidade da posição estatal a que tanto se aludiu, propiciou a própria superação do modelo civilista, para dar uma maior coerência na aplicação das teorias organicistas. Adminitiu-se então a imputação direta.

Se a vontade manifestada pelos agentes é a própria vontade das pessoas jurídicas e, assim, do Estado, também os fatos por eles praticados, ainda que danosos, haverão de ser imputados diretamente ao Estado.

Não obstante, procurava-se distinguir situações. Ora o Estado estaria agindo através de órgão, dando lugar à imputação direta, ora agiria através de representantes ou prepostos, o que dava lugar à imputação indireta.

Bastante elucidativa a exposição de PIERRE WIGNY (23): "Certains sont considerés comme des "organes" de la personne civile. Cette théorie se fonde, au moins implicitament, sur um anthropomorphisme audacieux. Un administrateur est à la societè commerciale ou un chef de département est à l'administration publique ce que les yeus ou les mains sont pour la per- 
sonne physique. Par ailleurs, une persone civile comme un particulier peut avoir à son service de simples préposés qui agissent pour le compte de leur commettant. Qu'il s'agisse d'orgnane ou de preposé, la responsabilité aquilienne de la pernone publique peut être engagèe. Mais dans le premier cas elle sera directe $e$ indirecte dans le second."

A distinção, evidentemente, tinha uma razão de ser. Se admitida a imputação direta, o Estado seria chamado à responsabilidade por fato próprio e, consequentemente não haveria porque, em princípio, aplicar-se os fundamentos da responsabilidade em relação ao comportamento de determinado agente, mas sobre o comportamento do órgão, no qual a pessoa dos agentes se funde, mesmo anonimamente, perante os terceiros lesados.

De outro lado, se o casso fosse de imputação indireta, o Estado seria chamado à responsabilidade por fato de outrem, por um fato do agente perfeitamente identificado. A imputação indireta pressupõe a imputação direta do fato a um agente determinado. Daí que, somente se determinada a responsabilidade do sujeito da imputaçâo direta, poder-se-ia cogitar da responsabilidade do sujeito da imputação indireta, perante o terceiro.

Esta distinção, embora formalmente coerente no que dizia respeito aos efeitos da imputação direta e indireta para a posterior liquidação da responsabilidade, era todavia incerta quanto aos seus próprios critérios distintivos.

A dificuldade, com efeito, residia na separação do fato do agente como órgão e do fato do agente como representante ou preposto. A doutrina e jurisprudência não forneceram critérios uniformes para a distinção. Como ainda salientou PIERRE WIGNY (24), às vezes se tomava em consideração a natureza das funções desenvolvidas pelos agentes, recorrendo-se inclusive àquela angustiante distinção entre atos de império e de gestao; outras vezes se considerava a parcela de autoridade pública que era atribuída aos agentes e, outras vezes ainda a situação regulamentar ou contratual dos agentes em confronto do Estado.

Tais critérios não se explicavam por si e careciam de interpretações que variavam ao sabor da doutrina e da jurisprudência.

Finalmente, é possível afirmar, que a noção de órgão culminou por abranger inteiramente a noção de preposto ou representante no âmbito do direito público, ao menos em tema de responsabilidade civil. 
Aliás, a noção de representante e preposto parecer estar se desvanecendo inclusive no âmbito do direito privado, também no campo da responsabilidade civil. Servem ainda estas expressões para substituir a noção de órgão em relação às pessoas físicas que, sob a sua direção, utilizam-se de outras pessoas para os mais variados cometimentos. Mas na prática, $\mathrm{o}$ ato do representante ou preposto acabam por ser imputados às pessoas físicas ou jurídicas como sendo atos próprio destas, mediante um mecanismo que AGUIAR DIAS (25) denomina de substituição.

Consoante este autor, "abstrai-se do fato ter sido o dano produzido materialmente pelo empregado. Este foi apenas o elo, o instrumento através do qual se realizou o fato danoso, isto é, através do qual se manifestou a falha de organização de que resultou que o serviço prejudicasse outrem. Do ponto de vista prático, é instrumento como o automóvel que se chocou contra outro ou que atropelou o transeunte, não servindo de objeção o fato de que o homem não se pode precisamente comparar à máquina, porque sua apregoada vontade, uma vez que não evita o dano, se anula, no que respeita à função, que não é causar acidente, mas servir".

Em conclusão, pode-se afirmar que o Estado atua sempre através de órgãos, podendo alguns inclusive ser identificados como órgãos de representação. Mas os fatos destes órgãos são sempre considerados como fatos próprios do Estado, extraindose então a regra de que a imputação é direta.

Excepcionalmente será possível cogitar de imputação indireta. Mas isto, quando o Estado ou uma outra pessoa jurídica de direito público deva ser chamada à responsabilidade subsidiariamente, pelo fato de outra pessoa, física ou mesmo jurídica, as quais não compõem a sua estrutura orgânica.

Isto se dá, segundo CELSO ANTONIO BANDEIRA DE MELLO (26), naquelas hipóteses em que estas outras pessoas, embora alheias à estrutura orgânica central do Estado "desempenham cometimentos estatais sob concessão ou delegação explícita (concessionárias de serviço público e delegados de função pública) ou implícitas (sociedades mistas e empresas do Estado em geral, quando no desempenho de serviço público propriamente dito). Isto porque não faria sentido que o Estado se esquivasse de responder subsidiariamente - ou seja - se a atividade lesiva só foi possível porque o Estado lhe colocou em mãos, o desempenho de atividade exclusivamente pública, embora geradora do dano". 


\section{V - QUALIDADE DE ÓRGĀO}

O agente, aquele que anima a pessoa jurídica de direito público como órgão, é obviamente um homem. Assim, os seus fatos tanto poderão consistir em fato do órgão, como poderão consistir em fato do homem. Os primeiros estão imputados diretamente ao Estado, os segundos serão imputados direta e exclusivamente ao agente, como homem.

Cumpre determinar, pois, as condições necessárias para que o fato do agente seja considerado fato do órgão ou fato do homem, para a exata aplicação dos fundamentos da responsabilidade civil.

Para tanto será preciso recorrer à própria noção de órgão e de seus elementos constitutivos.

$\mathrm{O}$ órgão compõe-se necessariamente de dois elementos. Um subjetivo, consubstanciado nos agentes que exercem os cometimentos estatais. Outro objetivo, que designa todo o conjunto de atribuições, operações, poderes, prerrogativas e instrumentos predispostos para os múltiplos cometimentos estatais, numa determinada unidade ou repartição da pessoa jurídica.

Sintetizando os dois elementos poder-se-á dizer que haverá atuação do órgão sempre que os agentes, porque integrados naquelas unidades funcionais, cujas competências devem vitalizar, ainda que sob diferentes graus hierárquicos e com variáveis atribuições, atuem se servindo ou mesmo abusando das prerrogativas predispostas para sua atuação.

Mais singelamente pode-se mesmo dizer que haverá atuação do órgão sempre que o fato do agente traduza o uso de uma prerrogativa estatal.

Não interessa, pois, o regime jurídico que disciplina a atividade do agente e tampouco a situação contratual ou regulamentar do agente em confronto do Estado. Pode mesmo tratar-se de um funcionário de fato, que compõe o órgão. É que "os terceiros entram em relação com os agentes administrativos, e, de boa-fé, os julgam legítimos representantes do poder público. Não seria possível exigir-se que fossem os particulares investigar da regularidade da investidura do agente, desde que exerça ele, plausível, pública e pacificamente as atribuições" (27).

Decorre daí que o decisivo para a transmudação do fato do agente em fato do órgão é que não se destaque materialmente daquele componente objetivo do órgão, ou seja, que não se destaque do exercício da função ou, ainda que praticado fora da fun- 
ção, que não se afaste das prerrogativas, meios e instrumentos próprios da função.

Tal como sugere RIVERO (28), tanto pode se compreender como fato do órgão aquele que não se destaca do serviço, como aquele em que o serviço não se destaca do fato danoso. Assim, por exemplo, inclui-se como fato do órgão, aquele do policial que, durante uma missão ou uma ronda, ainda que em período de folga, utiliza a arma e seu uniforme, que são instrumentos predispostos para o exercício de sua função, para o fim de intimidar um desafeto, o qual acaba sendo ferido também por um disparo.

\section{VI - FUNDAMENTO DA RESPONSABILIDADE - TEORIAS}

Paralelamente às teorias da imputação, como a da ficção e a do órgão, desenvolveram-se as teorias da responsabilidade, visando positivar os fundamentos pelos quais, em confronto da pessoa imputada, caberia o dever legal de reparar um dano ilegítimo.

De início já sobressai que somente depois que se admitiu a imputabilidade de um fato danoso ao Estado é que se tornou possível cogitar de sua responsabilidade. $E$ foi a teoria do órgão que, como se viu, justificou esta imputação.

A teoria do órgão, porém, em sua fase inicial, explicava apenas o fenômeno da formação da vontade da pessoa jurídica, a qual atuaria, todavia, através de representantes e prepostos, indicados pela lei ou por um ato jurídico. A imputação dos fatos era, pois, indireta e, nesse estágio, a teoria da responsabilidade civil estatal se assentava nos fundamentos tradicionais do modelo civilista.

O regime era então o da imputação indireta e o da responsabilidade subjetiva.

A liquidação da responsabilidade, em confronto do Estado, somente seria possível se provada a culpa ou mesmo o dolo do agente ao qual se imputava diretamente o mesmo fato. A culpa pessoal do agente era pois o fundamento exclusivo da responsabilidade estatal.

Com a melhor assimilação da teoria do órgão, admitindo-se a imputação direta de um fato ao Estado, ocorreu o primeiro grande passo para a chamada publicização do fundamento da responsabilidade estatal.

Isto ocorreu com a teoria da "faute du service", desenvolvida pela atividade pretoriana do Conselho de Estado francês e 
depois também assimilada pela jurisprudência e pelo próprio ordenamento jurídico de tantos outros países.

A culpa do serviço, também denominada de culpa impessoal, administrativa ou anônima, procurava fundamentar a responsabilidade do Estado independentemente da culpa pessoal do agente. Sendo o fato danoso considerado como um fato do órgão e por isso imputado diretamente ao Estado, como fato próprio, não haveria porque tomar em consideração a figura particular do agente para averiguar se agiu ou não com culpa.

Importava então levar em conta a culpa do órgão, medida pelo grau de defeituosidade do serviço a ele incumbido. Esta defeituosidade, segundo explicitou PAUL DUEZ (29), haveria de transparecer nas seguintes situações: o serviço não funcionou, o serviço funcionou mal, o serviço funcionou tardiamente.

O fundamento da responsabilidade continua sendo a culpa, aferida, porém, não mais sobre o comportamento pessoal de um agente determinado, mas sobre a atuação do órgão, que absorve em si a identidade dos agentes que o vitalizam. A culpa administrativa transparecerá sempre que se demonstrar que a atuação do órgão se apresentou, em concreto, abaixo dos padrões exigíveis, de acordo com as circunstâncias de tempo, lugar, instrumentos disponíveis, etc. A atuação defeituosa do órgão pressupõe evidentemente que os seus agentes, nele confundidos, repartindo atribuições, agiram com negligência, imprudência ou imperícia.

Não há que se distinguir, como pretendeu CELSO ANTONIO BANDEIRA DE MELLO (30) entre os fatos comissivos e os fatos omissivos do órgão, para afirmar que somente em relação aos segundos subsistiria como fundamento da responsabilidade a culpa, porque só aí ter-se-ia então que provar que o Estado incorreu em ilicitude "por não ter ocorrido para impedir o dano ou por haver sido insuficiente neste mister, em razão de comportamento inferior ao normal padrão legal exigível".

Acontece que os fatos comissivos, implicando na hipótese de mau funcionamento do serviço, pressupõe normalmente a culpa do órgão, a ponto de criar a ilusão que se pode prescindir deste fundamento. Com efeito, a existência de uma conduta comissiva ilícita revela sempre que ela merece uma tal qualificação porque se manifestou de modo inferior aos padrões normais de diligência, prudência ou perícia devidos por seu autor. Sentese, assim, que CELSO ANTONIO BANDEIRA DE MELLO (31) incorreu na mesma confusão que quis evitar, quando alertou da 
necessidade de se distinguir a objetividade de uma conduta da objetividade da responsabilidade.

Segue-se então a conclusão de que, segundo a teoria da culpa do serviço, o regime é o da imputação direta e da responsabilidade subjetiva.

Mas havia a constatação de que não eram somente os fatos ilícitos que causavam danos ilegítimos. Também os fatos lícitos podiam, como realmente podem, comprometer situações juridicamente protegidas dos administrados. Mas, nesses casos, o fundamento tradicional da culpa, ainda que na sua feição impessoal, não permitira a liquidação de qualquer responsabilidade.

Assim eram as hipóteses de um acidente de trabalho, no caso de obras públicas necessárias e perigosas por elas mesmas, porque ligadas a explosivos etc. Assim também as hipóteses de obras públicas, ainda que não perigosas, que acarretavam aos vizinhos danos que superavam os inconvenientes ordinários da vizinhança. Pense-se no caso do comerciante, devidamente licenciado, que por um longo período, em decorrência de obra pública, fica inibido de exercer o comércio, porque os clientes não tem acesso ao seu estabelecimento.

Mais uma vez inovou o Conselho de Estado francês, elaborando então outra teoria, segundo a qual a obrigação legal de reparar um dano podia ocorrer fora das hipóteses de culpa, mas com fundamento no risco de dano voluntariamente criado pelo Estado em detrimento de seus administrados.

Percebeu-se que fatos lícitos também causavam danos ilegítimos e, que assim, caberia o dever de reparação. Mas o fundamento jurídico desta reparação não foi imediatamente identificado. A alusão ao risco voluntariamente criado, como fundamento, sugeria, em última análise, que a responsabilidade decorria da vontade em provocar o dano e, assim, este fundamento não teria nítida distinção com o fundamento da culpa.

Incompatível, porém, a noção de culpa com a prática de fatos lícitos, pois, se assim são considerados, é porque são recomendados ou mesmo impostos pela ordem jurídica. Com efeito é mesmo um dever do Estado praticar fatos lícitos, que se presumem úteis à coletividade.

A busca do fundamento real da responsabilidade sem culpa não tardou a se revelar frutífera, ainda por obra do Conselho de Estado frances.

Em suma, ficou esclarecido que a obrigação de reparar um dano ilegítimo, quer decorrente de fato ilícito, quer decorrente 
de fato lícito, representa sempre uma realização da sanção por violação ao princípio da legalidade.

No caso dos fatos ilícitos, esta sanção atua quando ocorre um dano e este se apresenta como o resultado de uma conduta que violou o dever geral de cautela e diligência imposto a todos, no sentido de não comprometerem situações juridicamente protegidas.

No caso de fatos lícitos esta sanção atua, por sua vez, quando o dano se apresenta como o resultado de uma conduta que, apesar de atender ao dever geral de cautela, violou o dever específico de promover a exata distribuição dos encargos públicos entre toda a coletividade, na medida em que, visando-se criar uma utilidade para um grupo para toda a coletividade, onera-se particularmente um ou alguns administrados dentre o grupo ou dentre a coletividade.

Afirma-se assim a tese de que, quanto aos danos ilegítimos, decorrentes de fatos ilícitos, o fundamento é a culpa, entendida como violação ao dever de cautela e, quanto aos danos ilegítimos, decorrentes de fatos lícitos, o fundamento é o risco, mas entendido como violação específica ao dever de assegurar a isonomia.

Esta breve exposição já denota que a característica do dano ilegítimo, quando causado por fatos lícitos, é a particularização de um dano especial, a propósito do que se fala em dano anormal. E que se o dano foi compartilhado por todos os administrados a quem o fato visou beneficar, perderá o qualificativo de ilegítimo e, assim, não se configurará um dos pressupostos indispensáveis da responsabilidade.

Enfim, com a teoria do risco o regime será o da imputação direta e da responsabilidade objetiva.

\section{VII - CULPA DO AGENTE E CULPA DO SERVIÇO}

A teoria da culpa do serviço surgiu indubitavelmente como uma superação ao regime da imputação indireta e da responsabilidade subjetiva por culpa pessoal do agente.

Com efeito, pode-se dizer que o seu postulado básico foi o de admitir que o fato ilícito do agente, desde que qualificado como órgão, fosse diretamente imputado à pessoa jurídica e que a apuração da responsabilidade desta prescindisse da culpa pessoal, ou seja, prescindisse da possibilidade de responsabilização do próprio agente pelo mesmo fato. 
Em última análise, é a teoria da desconsideração da pessoa do agente, desde que qualificado como órgão, para fins de imputação direta e responsabilidade exclusiva da pessoa pública.

Desconsidera-se pois a pessoa do agente, mas se considera a sua conduta, o fato ilícito que se afirma.

Tanto é assim que se enfatizou a inutilidade da distinção entre "faute de service", caracterizada pelo fato ilícito de um agente nitidamente individualizado e a "faute du service", caracterizada, à sua vez, pelo fato ilícito de um ou mais agentes anônimos e possivelmente de difícil identificação (32). É que em ambos os casos a pessoa do agente deve permanecer estranha ao debate jurídico que se trava sobre a relação jurídica ressarcitória afirmada existente entre o terceiro lesado e a pessoa jurídica a que se imputa o fato ilícito.

Sob o domínio da teoria da culpa do serviço, porém, surgiram ainda na França algumas posições curiosas que, segundo se entende, comprometeram a coerência da própria teoria na sua aplicação.

Tratam-se, na verdade, de casuísmos que culminam por estabelecer um rompimento, sem justificação lógica, na questão da imputação e da responsabilidade decorrentes de um fato ilícito do órgão.

O primeiro casuísmo se liga à distinção que se fez entre "faute du service" e "faute personelle".

A "faute personelle" designa os casos em que um fato ilícito somente pode ser imputado diretamente à pessoa do agente, inadmitindo imputação, mesmo indireta da pessoa jurídica pública, sendo que somente o agente poderá pois ser chamado à responsabilidade.

Perfeitamente explicável esta distinção enquanto limitada àqueles fatos cujos agentes não podem ser qualificados como órgãos, porque os fatos a ele atribuídos se destacam materialmente do exercício da função ou das prerrogativas a ela inerentes.

A esta hipótese, porém, agregou-se uma outra. A do fato do agente que se destaca apenas psicologicamente das prerrogativas da função. Isto normalmente ocorre, segundo RIVERO (33), quando $o$ fato do agente, ainda que ligado materialmente àqueles componentes objetivos do órgão, é inspirado por interesses pessoais, revelando brutalidade ou intemperança do agente ou, ainda, quando o fato constitui crime.

A distinção se funda, como se vê, na maior ou menor censurabilidade à pessoa do agente. Este critério, porém, é impreciso e, 
além disto, inadequado.

LAUBADERE (34) reconhece a imprecisão "son critere est nuancé, difficile à enfermer dans des formules. Une des ces formules cependant est restée célèbre, celle qui fut donnée par Laferrière dans ces conclusions sur l'affaire Laumonnier-Carriol: II y a faute de service si l'acte donnageable est impersonnel, révèle un administrateur plus ou moins sujet à erreur, faute personnelle s'il révèle l'homme avec ses faiblesses, ses passions, ses imprudences".

De outro lado, como se disse, o critério é inadequado, tanto que não desqualifica substancialmente o fato do agente como sendo um fato do órgão. Com efeito, não se trata de um critério suficiente para afastar aquele antropomorfismo apregoado pela teoria do órgão. Este somente se rompe se o fato se destaca materialmente de uma prerrogativa estatal.

Semelhante posição se justifica apenas diante de uma peculiar situação política da França, onde se consagra a dualidade de jurisdições, uma administrativa e uma ordinária, sob o fundamento de que a separação de poderes veda à justiça ordinária a apreciação da legalidade dos fatos da Administração.

Os conflitos positivos de jurisdição entre as duas magistraturas provocou então a malsinada distinção, a fim de se assegurar à justiça ordinária a competência para responsabilizar pessoalmente $o$ agente a que se imputa direta e exclusivamente um fato ilícito.

Assim, se no curso de um processo, movido pelo particular contra o Estado, perante órgão da jurisdição administrativa, demonstra-se que o fato ilícito causador do dano revela especial cesurabilidade do agente que atuava no exercício de sua função, este órgão da jurisdição administrativa terá que reconhecer sua incompetência, a fim de que o pedido de reparação seja deduzido perante órgão da jurisdição ordinária, em confronto da pessoa do agente a que se imputa o fato.

Enfim, trata-se de um casuísmo que não tem porque ser assimilado, mesmo em países que adotam a dualidade de jurisdições. Esta distinção, atendo-se à possibilidade de responsabilização pessoal do agente, simplesmente atropela a possibilidade da responsabilidade civil estatal ou da pessoa jurídica pública.

É oportuno lembrar aqui que o fato ilícito do órgão nem sempre exclui a possibilidade de imputação do fato ao agente e, bem assim, a sua responsabilidade civil, fundada na culpa pessoal. Quanto aos fatos regidos pelo direito público, porém, cons- 
tata-se que esta possibilidade de responsabilização pessoal do agente está mitigada.

E que diante do caráter diferenciado das atividades que ans agentes-órgãos incumbe desempenhar, a própria teoria da culpa do serviço impediu a imputação e responsabilidade dos agentes por falhas ou erros que, embora evitáveis segundo os padrões normais do serviço, deverão ser tidos como escusáveis em relação aos agentes, diante da má organização administrativa, considerada no seu conjunto.

Todavia, se a falha é tal, a ponto de não ser considerada escusável, porque revela a ocorrência de um crime ou uma atuação movida por propósitos pessoais, etc., subsiste então a possibilidade ou mesmo o dever de imputação e responsabilidade em confronto do agente.

Mas há que se notar que tais considerações não devem absolutamente afastar a aplicação da teoria da culpa do serviço naquela relação jurídica ressarcitória externa que se afirma existente entre o terceiro lesado e a pessoa pública, por fato ilícito do órgão. Nessa relação considera-se objetivamente a conduta do agente-órgão e sobre ela se opera a investigação da culpa do serviço. Não se considera pois a pessoa do agente, para investigação de sua culpa pessoal. A culpa, assumida pela pessoa jurídica, continua sendo medida pelo grau de defeituosidade do serviço em relação aos padrões normais e possíveis da atividade em questão.

A imputação e responsabilização pessoal do agente terão lugar em outra relação jurídica ressarcitória, interna, que se afirma existente na intimidade da pessoa jurídica, entre ela e seu agente. Nessa relação é que terá relevância a conduta personalizada do agente, para a liquidação da sua responsabilidade civil. Se o fato eventualmente constitui crime dará lugar ainda a uma terceira relação jurídica, desta feita entre o agente e a coletividade, esta representada pelo Estado-Sociedade, para atuação das sanções penais cabíveis.

O segundo casuísmo da teoria da culpa do serviço, que compromete também sua unidade e coerência, diz respeito a distinção que se procura estabelecer entre "faute du service" e "faute de I'homme".

A distinção prende-se, em última análise, segundo se entende, a casos em que teria lugar a imputação indireta de um fato do agente à pessoa pública, cuja responsabilidade dependeria da comprovação da culpa pessoal do agente. Fala-se, porém, em culpa do homem, porque se tem em cogitação os fatos que os 
agentes devem desempenhar pela pessoa jurídica pública, sob um regime de direito privado, em situação idêntica a de qualquer particular.

PAUL BENOIT (35) cita o exemplo dos acidentes de trânsito, envolvendo veículos e agentes administrativos, que circulam pelas vias públicas nas mesmas condições jurídicas dos veículos e motoristas particulares, sustentando que, dada a identidade de problemas, a liquidação da responsabilidade deve também ser operada de modo idêntico. Apregoa-se, enfim, a utilização dos critérios tradicionais civilistas.

A identidade de situação, no plano do direito público e do direito privado, não compromete porém, a aplicação da teoria da culpa do serviço, antes recomenda a sua utilização também no direito privado.

Com efeito, conforme já se aludiu, no âmbito do direito público a noção de órgão culminou por abranger inteiramente a noção de representante e preposto, noções estas que parecem também fadadas a se desvanecerem no âmbito do direito privado. Não importa pois o regime jurídico da atividade para a qualificação do agente como órgão. Atuando ele pela pessoa jurídica, para a consecução de seus cometimentos próprios ou utilizando-se dos instrumentos predispostos para estes mesmos cometimentos, assume o agente a condição de órgão. Consequentemente, o seu fato é imputado diretamente à pessoa pública e em confronto dela se opera a liquidação da responsabilidade, sem considerações quanto à pessoa do agente; apenas se considera objetivamente a sua conduta.

Ainda que se trate de atividade regida pelo direito privado, a investigação da culpa da pessoa jurídica prescinde da individualização do agente e, conseqüentemente da sua culpa pessoal ou, como se diz, da investigação da culpa do homem.

Basta que se contraponha a conduta supostamente ilícita com os padrões de diligências possíveis e desejáveis para a consecução de determinada atividade, ainda que regida pelo direito privado.

A maior probabilidade da identificação dos agentes, nestes casos, caracteriza um típico caso de "faute de service", pelo qual a pessoa do agente permanece, como sempre ocorre na "faute du service" estranha ao debate jurídico que se trava na relação jurídica ressarcitória externa.

Concluindo, tem-se que a culpa do serviço é a teoria aplicada para a liquidação da responsabilidade da pessoa jurídica pública em todos os casos em que se cogita de um fato ilícito do agente 
qualificado como órgão. Referenda ela o regime da IMPUTAÇĀO DIRETA e da RESPONSABILIDADE SUBJETIVA. Esta teoria, complementada, pela teoria do risco, que marca o regime de IMPUTAÇÃO DIRETA e da RESPONSABILIDADE DE OBJETIVA, demonstra que a responsabilidade civil das pessoas jurídicas públicas situa-se totalmente, no âmbito do direito público.

\section{VIII - RESPONSABILIDADE E CAUSALIDADE}

Conforme já se aludiu anteriormente, sustenta-se que a causalidade não é um pressuposto da responsabilidade. Pressuposto é a simples afirmação quanto a existência de uma relação jurídica ressarcitória, envolvendo, de um lado, um dano ilegítimo e, de outro, um fato danoso imputado a diversa pessoa.

A causalidade, segundo se entende, promove a investigação da real existência da relação ju rídica afirmada. E, nesse sentido, ela opera sobre os pressupostos, não se confundindo com eles. A causalidade consiste, em suma, na própria liquidação da responsabilidade.

É que no momento de se estabelecer, concretamente, a relação entre o suposto dano ilegítimo e o fato danoso, ter-se-á que por em evidência o adequado fundamento da responsabilidade.

Se o fato imputado à pessoa pública é ilícito, o fundamento da responsabilidade será a culpa e assim suficiente será para a caracterização do dano ilegítimo, que o mesmo seja especial.

De outro lado, se o fato imputado à pessoa pública é lícito, o fundamento da responsabilidade será a necessidade de distribuição equitativa dos encargos públicos e, nesse passo, a caracterização da ilegitimidade do dano requererá que o mesmo seja, além de especial, anormal.

Diz-se, então, que a causalidade não se realizará quando se constatar que o dano se deu por culpa exclusiva da vítima ou por força maior e, nos casos de responsabilidade subjetiva, em decorrência de um caso fortuito.

$\mathrm{Na}$ realidade, estas hipóteses são excludentes da própria responsabilidade, porquanto afastam a possibilidade de aplicação dos seus fundamentos.

Uma vez feitas estas considerações sobre imputação, responsabilidade e causalidade, acredita-se que podem ser explicadas as variadas opiniões em tema de responsabilidade estatal, cujas divergências entretanto geralmente não comprometem a aplica- 
ção correta do seu regime jurídico, já que normalmente são de natureza terminológica.

Assim, quando se afirma que a responsabilidade é exclusivamente objetiva, porque não se leva em consideração a pessoa dos agentes, quer-se na verdade referir, não ao fundamento da responsabilidade, mas ao fundamento da imputação, que é sempre direta.

De outro lado, quando se diz que não importa a culpa pessoal dos agentes para a liquidação da responsabilidade civil da pessoa pública, em razão de fatos ilícitos, não se quer negar a subsistência do regime da responsabilidade subjetiva. Apenas se nega que tenha aplicação em tais casos os fundamentos tradicionais do direito privado, porque substituidos pelo fundamento da culpa do serviço.

Por fim, quando se afirma que para a configuração da responsabilidade civil estatal basta estabelecer o nexo causal entre o fato e o dano invocados, não se quer afirmar que a responsabilidade seja exclusivamente objetiva. É que como foi dito acima, a causalidade implica na própria liquidação da responsabilidade e por isso, não se realiza sem que se ponha em evidência os fundamentos adequados a estabelecer a real existência de uma relação entre dano ilegítimo e o fato danoso. 


\section{ANOTAÇÕES BIBLIOGRÁFICAS}

1.RIVERO, Jean, Droit Administratif, Dalloz, Paris, 1960, p. 223;

2.BANDEIRA DE MELLO, Celso Antonio, Ato Administrativo e Direitos dos Administrados, Ed. Revista dos Tribunais, 1981, pp. 125/126;

3.DE PLACIDO E SILVA, Vocabulário Jurídico, Ed. Forense, 1967, vol. II, p. 802;

4.DE PLACIDO E SILVA, ob. cit., vol. III, p. 1368;

5.DE PLACIDO E SILVA, ob. cit., vol. III, p. 1368;

6.WIGNY, Pierre, Droit Administratif, Ed. Bruylant, Bruxelles, 1953, pp. 294/300;

7.DINIZ, Maria Helena, Curso de Direito Civil Brasileiro, Saraiva, 1984, vol. 7, p. 33;

8.BANDEIRA DE MELLO, Celso Antonio, ob. cit., p. 34;

9. RIVERO, Jean, ob. cit., p. 229;

10.DUEZ, Paul e DEBEYRE, Guy, Traitè de Droit Administratif, Paris, 1952, p. 419;

11.DINIZ, Maria Helena, ob. cit., p. 33;

12.BANDEIRA DE MELLO, Celso Antonio, Apontamentos Sobre os Agentes e Órgãos Públicos, Ed. Revista dos Tribunais, 1972, p. 62;

13. BANDEIRA DE MELLO, Celso Antonio, ob. cit., p. 62;

14.WIGNY, Pierre, об. cit., p. 290;

15.MOACIR PORTO, Mario, Responsabilidade Civil Decorrente da Guarda da Coisa, in Revista dos Tribunais, vol. 573, p. 15;

16.AGUIAR DIAS, José de, da Responsabilidade Civil, Ed. Forense, 1960, vol. II, p. 454 ;

17. BANDEIRA DE MELLO, Celso Antonio, Atos Administrativos e Direito dos Administratos, ob. cit., p. 150 ;

18.SERPA LOPES, Miguel Maria de, Curso de Direito Civil, Ed. Freitas Bastos, 1960, vol. I, pp. 347/348;

19. SILVA PEREIRA, Caio Mario da, Instituições de Direito Civil, Ed. Forense, 1970, vol. I, pp. 180/181;

20.WIGNY, Pierre, ob. cit., p. 296;

21.BANDEIRA DE MELLO, Oswaldo Aranha, Princípios Gerais de Direito Administrativo, Forense, 1974, vol. II, p. 77;

22.SERPA LOPES, Miguel Maria de, ob. cit., pp. 348/349;

23. WIGNY, Pierre, ob. cit., p. 290;

24. WIGNY, Pierre, ob. cit., p. 291;

25. AGUIAR DIAS, José de, ob. cit., pp. 578/579;

26. BANDEIRA DE MELLO, Celso Antonio, Ato Administrativo e Direitos dos Administrados, ob. cit., p. 141;

27. BARROS JUNIOR, Carlos S., Teoria Jurídica dos Funcionário de Fato, in Revista de Direito Administrativo, vol. 100, p. 55;

28.RIBERO, Jean, ob. cit., p. 247;

29.DUEZ, Paul e DEBEYRE, Guy, ob. cit., p. 423;

30.BANDEIRA DE MELLO, Celso Antonio, Ato Administrativo e Direitos dos Administrados, ob. cit., pp. 142/143;

31. BANDEIRA DE MELLO, Celso Antonio, Ato Administrativo e Direitos dos Administrados, ob. cit., p. 135;

32. RIVERO, Jean, ob. cit., p. 234;

33. RIVERO, Jean, ob. cit., pp. 244/245;

34.LAUBADERE, André de, Manuel de Droit Administratif, Librarie General de Droit et de Jurispurdence, Paris, 1951, p. 118;

35. BENOIT, Paul, Le Droit Administratif Français, Dalloz, Paris, 1968, pp. 682/683. 